\title{
Home Schooling sebagai Pendidikan Alternatif
}

\section{Akhmad Kasinu}

Dosen Sekolah Tinggi Agama islam Negeri (STAN) An-Nawawiyah Purworejo

Abstract: Schools as an educational institution which most people regard as the main institution in educating children today begin to doubt. This institution is deemed not able to optimally to achieve these noble ideals. School educational institutions is felt most people only as an institution that targets only the curriculum, concemed with value and achievement as measured on the basis of ranking, are not concerned with the development potential of children, even more, school is considered as an institution that student creativity into it. So these days many parents begin to look to the concept of education who once glorious "home schooling" to overcome the problems. Many reasons why home schooling began in great demand. This paper will examine why home schooling should be used as an altemative model of education to answer the lack of success of the school institution in realizing the ideals of the above.

Keywords: Home Schooling, Education, Educational Institution.

\section{Pendahuluan}

Kualitas sumberdaya manusia yang dimilikioleh suatu bangsa/ negara akan senantiasa meningkatkan daya saing negara tersebut. Di banyak negara, termasuk di negara maju pun, akan membangun dunia pendidikan tanpa harus berhenti. Di negara maju, cenderung selalu meningkarkan investasinya dalam dunia pendidikan. Sayangnya, saat ini Indonesia belum mampu memandang pendidikan sebagai investasi jangka panjang. Behum ada political will yang serius terhadap pembangunan sektor pendidikan. Akibarnya, kualitas dan daya saing bangsa ini semakin merosot, jika dibandingkan negara-negara di Asia sekalipun. Oleh karena itu, perlu upaya yang sistematis untuk memperbaiki dan membangun sektor pendidikan

Miarao mengatakan bahwa pendidikan merupakan proses bagi suatu bangsa untuk mempersiapkan generasi mudanya untuk menjalankan kehidupan dan untuk memenuhi tujuan hidup secara efektif dan efesien. ${ }^{1} \mathrm{Hal}$ ini sejalan dengan 
tujuan pendidikan nasional sebagaimana tertuang dalam UU No. 20 Tahun 2003 tentang Sistem Pendidikan Nasional bahwa pendidikan nasional bertujuan untuk mencerdaskan kehidupan bangsa dan mengembangkan manusia Indonesia seutuhnya yaitu manusia yang beriman dan bertakwa kepada Tuhan dan berbudi pekerti luhur, memiliki pengetahuan dan keterampilan kesehatan jasmani dan rohani, serta rasa tanggung jawab kemasyarakatan dan kebangsaan. ${ }^{2}$

Untuk mewujudkan hal itu, negara tidak hanya mengakui sistem pendidikan formal dan nonformal, tetapi hendaknya juga mengakui adanya pendidikan alternatif bome schooling. Pendidikan alternatif di rumah (bome scbooling) bertujuan untuk menampung anak-anak yang tidak tertampung oleh sekolah formal. Ketika sekolah telah terjebak dalam hegemoni dehumanisasi dan sekolah nonformal juga terjebak dalam industrialisasi dan komersialisasi, maka pendidikan alternatif yang mampu menerobos status quo, menjadi pilihan.

\section{Pengertian Home Schooling}

Seto (dalam Basrowi, 2006) mendefinisikan bome schooling menjadi kesempatan karena terdapat komunikasi yang teratur dan terarah di luar sekolah dan seseorang memperoleh informasi, pengetahuan, latihan maupun bimbingan sesuai dengan usia dan kebutuhan kehidupan. 3 Tujuan bome schooling adalah mengembangkan tingkat keterampilan, sikap dan nilai-nilai yang efisien dan efekrif dalam lingkungan keluarga, pekerjaan bahkan lingkungan masyarakat dan negaranya. Lebih lanjut, Phillips H. Comba (dalam Basrowi, 2006) mengungkapkan bahwa pendidikan bome schooling adalah kegiatan pendidikan yang teroganisir yang diselenggarakan di luar sistem formal, baik tersendiri maupun merupakan bagian dari suatu kegiatan yang lugas, yang dimaksudkan untuk memberikan layanan kepada sasaran didik tertentu dalam rangka mencapai tujuan-tujuan belajar. ${ }^{4}$

Batasan di atas, walaupun redaksinya berbeda, tetapi pada pokoknya sama, yakni kegiatan pendidikan di luar sekolah ditandai oleh: (a) adanya pengorganisasian, (b) adanya perencanaan isi pendidikan (c) adanya urutan materi, (d) adanya kredebilitas sekalipun kurang memegang peranan penting, (d) jangka waktu pendek, (c) tujuan spesifik, (f) learning for life not sitting for examination, 
(g) sasaran/subjek meliputiorang dewasa, anak tuna sekolah anak pra-sekolah, serta anak-anak sekolah bagi hal-hal yang tidak diperolehnya di sekolah.

Meninjau kedua batasan pendidikan bome scbooling diatas, maka tidak mustahil disebut sistem pendidikan karena dalam pendidikan alternatif, bome schooling telah merniliki "a set of component so related and organized as to attain the ends for wbich the sistem is establisbed ...". Dalam batasan di atas, sistem berarti kumpulan komponen (unsur-unsur) yang saling berhubungan dan diorganisir untuk mencapai tujuan. Pendidikan bomeschooling telah terkandung semua unsur yang disyaratkan oleh sesuatu sistem seperti anak didik, pendidik, waktu materi dan tujuan. Dengan sistem pendidikan bome schooling, berarti adanya suatu pola tertentu untuk melakukan pekerjaan/fungsi, yakni mendidik, pekerjaan/fungsi yang berbeda dengan pekerjaan/fungsi sistem pendidikan formal.

Sistem pendidikan ini bukanlah karya atau ide orang-orang tertentu, tetapi beberapa ahlipendidikan telah berkontribusi dalam kelahiran dan perkembangan home schooling. Berapa nama seperti John Dewey, John Holt, Ivan Illich, Maria Montesori, dan AS Neill banyak disebut sebagai kontributor dalam mengembangkan sistem bome schooling.

John Dewey merupakan perintis bome sobooling. Di penghujung tahun 1800 -an, Dewey berpendapat bahwa proses belajar merupakan penjelajahan aktif dari seorang anak. la menekankan pentingnya "learming by doing". Konsep ini menghasilkan konsep "progresive education". Dewey menekankan kebebasan dan kreativitas manusia, dan menjadikan pengalaman belajar sebagai pengalaman yang utuh. Anak secara aktif menemukan, mengkaji, dan menerapkannya. ${ }^{5}$

Pemikiran Dewey memang tidak menghasilkan secara langsung konsep bome scbooling, tapi menjadi titik awal yang bagus, dalam mengkritik secara keras terhadap sistem pendidikan sekolah yang otoriter, tidak demokratis, dan mengekang kebebasan murid dalam belajar, dan menemukan informasi yang membangun mereka ${ }^{6}$ Home schooling itu sendiri lahir dari ketidakpuasan terhadap sekolah konvensional.

Tokoh lain yang banyak disebut adalah John Holt, seorang guru yang bekerja pada dua sekolah swasta. Holt mengamati tingkah-laku siswa di kelasnya dan kemudian menulis buku How Children Fail? (1967). Holr mengungkapkan bahwa disana anak-anak belajar di sekolah hanya untuk memuaskan keinginan gurunya, 
menghindari rasa dipermalukan, dan anak hanya belajar apa yang diajarkan kepada mereka. Akhirnya, faktor yang membedakan antara siswa yang baik dan tidak baik hanyalah kemampuannya. Siswa yang baik tidak akan lupa terhadap apa yang sudah diajarkan oleh gurunya dan dapat menjawab dengan baik dalam ujian akhir.

Selain buku tersebut, Holt masih menulis beberapa buku lagi di tahun berikutnya seperti: The Underachieving School (1969); What Do I Do Monday? (1970); dan Freedom and Beyond (1972). Holt banyak mempertanyakan peran sekolah dan bagaimana seharusnya sekolah dapat lebih baik dalam mendidik anak-anak, bahkan dia mengajak pembacanya bukan untuk sekadar memperbaharui sistem pendidikan sekolah tapi juga untuk memikirkan alternatif lain dari model sekolah. Pemikiran Holt sebenarnya sangat dipengaruhi oleh Ivan Illich.

Illich adalah seorang pastur bagi warga Puerto Rico di New York. Illich menganalisis bahwa sekolah menjalankan pendidikan lebih sebagai komodoti yang dijual daripada menyediakan proses belajar sepanjang hayat. Menurut Illich, hal itu membuat pemisahan kelas-kelas masyarakat yang makin kuat dan orang mengukur orang lain dengan ukuran-ukuran yang tidak adil. Ivan Illich sangat radikal dalam melihat pembaharuan pendidikan pada watu itu bahkan dia mendorong orang untuk keluar dari sekolah dan membentuk jaringan belajar (learning web). Jaringan ini adalah untuk membantu siswa akses kepada sumber pembelajaran sebanyak-banyaknya, yang terdiri atas empat komponen, yaitu (1) layanan referensi mengenai objek pendidikan; (2) pertukaran keahlian; (3) komunikasi pasangan sebaya; dan (4) layanan referensi mengenai narasumber dalam bidang yang lugas.

Home schooling sebenarnya bukan hal baru. Konsep ini sudah diterapkan sejak zaman raja-raja Eropa. Saat itu, anak-anak raja dan bangsawan karena alasan keamanan dan status sosial, jarang disekolahkan di luar lingkungan kerajaan. Seiring dengan perkembangan zaman, konsep ini di adopsi oleh negaranegara maju, seperti Amerika. Ternyata model sekolah rumahan itu berhasil. Amerika sudah melaksanakan bome schooling 40 tahun terakhir; home scbooling sudah menjadi suatu yang legal tahun 1982. Di Indonesia, bome sobooling mulai dilakukan terutama di perkotaan. Model yang berkembang di Indonesia, 
mayoritas mencontoh model yang berkembang di Amerika. Model ini membutuhkan kedisiplinan, komitmen, dan tanggung jawab yang tinggi.

\section{Keberadaan Home Schooling}

Beberapa orangtua di kota besar mulai melirik konsep home sobooling. Mereka melakukan hal itu setelah tak puas dengan sistem pendidikan yang ada, misalnya sekolah yang hanya mengejar target kurikulum, atau mementingkan nilai seperti prestasi yang diukur dari ranking, bukan pada potensi anak, atau tidak melibatkan anak lebih aktif dan sebagainya.

Ada beberapa hal yang melatarbelakangi masyarakat berpandangan positif terhadap bome schoaling. Home schooling tumbuh karena penghargaan terhadap pentingnya keunikan setiap individu dalarn belajar dan pengalaman belajar yang utuh. Home schooling tumbuh dari ketidakpuasan masyarakat terhadap sistem pendidikan sekolah yang justru dianggap menekan kreativitas siswa. Home schooling menjadi salah satu pendidikan alternatif karena sekolah tidak lagi menjadi tempat di mana anak-anak terlindung dari kekerasan (bullying). Sekolah justru menjadi pemisah anak dari dunianya.

Meski konsep tersebut bukan pilihan praktis bagi banyak orang, namun sebagian orangtua yang bertempat tinggal di kota besar lebih memilih pendidikan di rumah bagi anaknya. Keuntungan dan manfaat yang bisa diperoleh antara lain, (1) "siswa rumahan" justru lebih dewasa dan secara sosial lebih mampu menyesuaikan diri; (2) di rumah mereka dapat berinteraksi dengan orang-orang dari berbagai lapisan usia; (3) di rumah mereka dapat membuat pertanyaan, dan pertanyaan itu membuat anak termotivasi untuk melihat jawaban dari pertanyaannya; dan (4) di rumah, anak benar-benar dapat bekerja secara mandiri tanpa dipengaruhi guru maupun teman lainnya?

Berdasarkan uraian di atas, dapat dipahami bahwa setidaknya ada tiga alasan orangtua tidak memilih menyekolahkan anaknya di sekolah dan memilih bome schooling. Pertama, anak-anak di sekolah dikelompokan menurut rentang batas usia yang sempit, sedangkan di rumah mereka dapat berinteraksi dengan orangorang dari berbagai lapisan usia. Kedua, banyak pekerjaan-pekerjaan di kelas konvensional disampaikan dengan komunikasi searah, dari guru ke murid. Pendidikan berbasis rumah membalikan proses itu, kebanyakan pertanyaan 
dikemukakan oleh siswa, dan itu membuat siswa tetap termotivasi. Dia ingin melihat jawaban dari pertanyaannya. Ketiga, walaupun, kelihatannya anak-anak belajar bersosialisasi di sekolah, tetapi sebenarnya tidak. Mereka belajar "sendirisendiri tetapi barengan". Di rumah, anak-anak benar-benar mengerjakan tugas secara mandiri.

Pendidikan berbasis rumah terkait dengan hasil pendidikan yang bersifat personal dan fleksibel. Anak-anak tidak dipaksa untuk menyelesaikan suatu kurikulum. Di rumah, ada umpan-balik langsung dan segera tentang capaian anak memahami bahan yang baru saja diajarkan. Anak merasa bahagia, tidak ada perasaan segan dan malu untuk mengatakan tidak mengerti.

Para "pelajar rumah" tampaknya lebih mampu mengembangkan disiplin yang lebih besar. Secara otomatis, mereka mau belajar tanpa tergantung pada orang lain. Mereka berinisiatif menemukan sesuatu yang perlu diketahuinya, dan orangtua (anak lebih banyak belajar bersama mereka) menjadi pendamping yang dibutuhkan untuk aktif mencari informasi. Orangtua diibaratkan sebagai "manajer pendamping dalam belajar".

Dengan menggunakan berbagai fasilitas yang dimiliki di rumah, komputer misalnya, mereka secara ekstensif bisa menggunakannya untuk menulis dan mengerjakan tugas. Mereka lebih bisa mempersiapkan diri secara langsung untuk menghadapi dunia keda di masa depan.

Masyarakat yang mendukung konsep ini menganggap bahwa guru bukan lagi dipandang sebagai "lemari pengetahuan"; tetapi sekarang ini, radio, TV, majalah, museum, perpustakaan, pusat keagamaan, video, dan sebagainya. Di atas itu, semua bisa menjadi "jalan raya bebas hambatan" untuk mengubah secara dramatis kemamuan anak-anak.

Dengan belajar di rumah, anak-anak tidak lagi menunggu untuk diajar. Mereka sudah terbiasa mengelola pelajaran sendiri, mengikuti rencana belajarnya sendiri, yang jelas semua ini menjadi bagian alamiah dari pendidikan mereka. Home schooling bukan berarti mengacaukan pendidikan dengan sekolah. Sekolah tidak bisa lagi dianggap, sebagai satu-satunya sumber pembelajaran. Sekolah juga bukan satu-satunya, pusat pengetahuan. Guru bukan lagi sebagai satusatunya orang yang berperan sebagai pendamping dan penunjang belajar anak. Belajar harus terjadi dan berlangsung setiap saat, di setiap tempat. Belajar 
"setiap saat dan selama hayat". Belajar harus dilakukan oleh anak-anak, kapan saja mereka membutuhkannya.

Home schooling saar ini memang masih menjadi perbincangan banyak orang. Akan tetapi, sebagian masyarakat mempunyai keyakinan bahwa bome schooling bisa menjadi model pendidikan alternarif di tengah keraguan terhadap mutu pendidikan, sekaligus sebagai jalan keluar atas mahalnya biaya sekolah. Di samping menjadi solusi jitu, metode ini memerdekakan anak agar tidak terbelenggu.

Konsep bome scbooling akan menciptakan generasi yang berkualitas karena dididik sesuai minat dan bakat anak. Sistem itu perlu diterapkan kepada anakanak dalam rangka memerdekakan anak. Rumah sudah saatnya menjadi tempat berlangsungnya proses pendidikan, dalam menciptakan manusia yang berbudaya.

Standar pendidikan dengan kurikulum yang berganti-ganti, ujian nasional yang mematok angka kelulusan menjadikan anak-anak terbebanidengan muaran yang sangat berat. Padahal, model seperti itu tidak menyentuh sisi pendidikan dan pernbelajaran. Hal itu membuat tujuan utama pendidikan menjadi terlupakan. Orangtua hendaknya lebih mengedepankan proses pembelajaran di rumah dari pada hasil nilai ujian akhir yang cenderung "semu", kualitas pribadi dan penguasaan anak terhadap sesuatu dalam bome schooling akan jauh lebih baik dibandingkan anaksekolahan.

Dengan bome schooling, anak akan mendaparkan kebebasan belajar yang lebih baik. Anak akan mampu mengubah mental, watak, dan temperamennya sehingga tidak menjadi generasi yang rusak, yang akan menghancurkan bangsa. Home scbooling diyakini dapat memperbaiki berbagai kelemahan sistem pendidikan di sekolah. Masyarakat harus berani keluar dari sistem sekolah ini. Adanya jual beli gelar dan ijazah palsu sebagai bukti orientasi pendidikan sudah bukan lagi untuk menjadi manusia berbudaya, tetapi manusia yang tidak memiliki budaya akademis.

\section{Home Schooling sebagai Pendidikan Alternatif}

Pembahasan tentang pendidikan alternatif bome schooling memang merupakan hal yang menarik karena: (1) merupakan sistem baru dalam dunia 
pendidikan yang bentuk dan pelaksanaannya berbeda dengan sistern sekolah yang sudah ada; dan (2) terdapat hal-hal yang sama-sama pentingnya bila dibandingkan dengan sistem sekolah yang sudah ada.

Berdasarkan kajian teori, ada beberapa alasan orangtua lebih mem;ifih memberikan pendidikan di rumah dari pada di sekolah karena:

a. Orangtua melihat bahwa kemampuan anak-anak mereka unik sehingga harus ditangani secara unik pula. Sekolah dipandang tidak akan sanggup memenuhi hal ini karena tanggung jawab yang besar kepada siswa lain yang jumlahnya besar;

b. Adanya kehawatiran orangtua melihat anak-anaknya terjebak dalam peer pressure yang memberikan dampak buruk bagi perkembangan psikologis dan kepribadian anak;

c. Orangtua melihat kecenderungan anak pergi ke sekolah karena kebiasaan masyarakat, tapi bukan kebutuhan dan kesadarannya sendiri;

d. Adanya anggapan orangtua bahwa sckolah dipandang hanya akan memberikan beban yang berat dalam bentuk tugas, ulangan, dan ujian-ujian yang diterima anak-anak tidak dengan sukacita;

e. Dengan bersckolah di rumah, orangtua jadi mengenal potensi anak lebih baik dan hubungan antaranggota keluarga menjadi lebih kuat; dan

f. Dengan bersekolah di rumah, belajar tidak lagi menjadi beban yang berat tapi menjadi sesuatu yang menyenangkan.

Mereka yang melaksanakan pendidikan di rumah ada kecenderungan mengambil kurikulum dari negara luar seperti Singapura, Malaysia bahkan dari Amerika. Namun, ada juga yang mengadop kurikulum dari Dinas Pendidikan. Mereka yang mengikuti kurikulum yang berlaku di Indonesia, biasanya pada akhir masa belajar, orangtua mendaftarkan anaknya untuk mengikuti Ujian Paket, A, B, atau C.

Walaupun bame schooling dapat dikatakan produk Amerika, namun dalam konteks Indonesia, sistem pendidikan ini memiliki akar budaya Indonesia yang cukup kuat, yaitu konsep kekeluargaan. Paradigma keluarga sangat kuat dalam budaya Indonesia, di mana setiap keputusan individu selalu terkait dengan kontek keluarga. Bukan hanya dari segi budaya, tapi tokoh-tokoh pendidikan nasional seperti Ki Hajar Dewantara dan Mohammad Syafei juga telah 
memberikan pemikiran-pemikiran yang memungkinkan bome scbooling kontekstual dalam masyarakat Indonesia. ${ }^{8}$ Dengan demikian, bome schooling yang dikembangkan bukan merupakan produk asing semata.

Ada beberapa hambatan pelaksanaan bome scbooling: (1) hanya dapat dilakukan oleh keluarga menengah ke atas. Keluarga dengan tingkat ekonomi rendah tidak bisa mendidik anak di rumah karena seluruh waktu yang dimiliki digunakan untuk mencari uang; (2) Tingkat pendidikan orangtua rata-rata belum mencukupi untuk melaksanakan bome schooling, dan (3) Pemerintah masih menekankan program wajib belajar sembilan tahun yang mewajibkan anakanak masuk sekolah.

Secara umum, dapat diungkapkan bahwa sebagian orang beranggapan bila memperbincangkan masalah pendidikan, maka orientasinya ke dunia sekolah dan menghubungkan guru dengan murid. Mereka kurang menyadari bahwa sebelum seseorang anak menjadi murid, anak-anak telah memperoleh pendidikan yang diberikan oleh keluarganya terutama ayah dan ibunya.

Realitas lain, di lingkungan kerja makin dibutuhkannya berbagai macam keahlian dalam menyongsong kehidupan yang semakin kompleks dan penuh tuntutan, maka wajar jika masyarakat menghendaki berbagai penyelenggaraan pendidikan dengan program-program keahlian. Sistem persekolahan mengharuskan siswa berada dalam bentuk menyeluruh dan keahlian yang sejenis sehingga mereka terasing dari pengetahuan dan keahlian lain. Kelemahan sistem persekolahan inilah yang memungkinkan kegiatan pendidikan bome sobooling menerobosnya sehingga terungkaplah pengetahuan dan keahlian yang selama ini dirasakan sebagai kekurangan.

Di masyarakat, ternyata tersebar berbagai sumber belajar yang tidak terbilang banyaknya. Sumber belajar yang demikian dapat berupa makhluk hidup maupun benda-benda mati. Orang-orang yang ahli, pintar, terampil, penuh pengalaman merupakan sumber belajar yang bersifat manusiawi. Dari mereka, dapat diperoleh dan ditemukan berbagai pengamalan, keterampilan yang bisa bermanfaat bagi anak.

Kecenderungan belajar seseorang tidak bisa dihalangi oleh siapapun dan keinginan untuk belajar ini dapat timbul kapan saja dengan tidak memandang jenis kelamin, usia, latar belakang pendidikan, tempat tinggal, atau lainnya. 
Gejala demikian semakin meningkat karena adanya konsep "learming society" yakni konsep tentang keadaan masyarakat yang di dalamnya terkandung suasana gemar belajar dari masyarakat yang bersangkutan. Kecenderungan ini juga diperkuat oleh kemajuan ilmu dan teknologi seperti radio, televisi, media cetak atau elektronik, internet, dan kemudahan komunikasi dengan berbagai fasilitas. Tersebarnya ahli pengetahuan yang profesional di berbagai belahan dunia, semakin dapat memenuhi keinginan belajar mandiri.

Dalam hubungan dengan sistem pendidikan, maka pendidikan alternatif bome schooling berbeda dengan sekolah umum. Perbedaannya: (1) Sekolah tidak lagi bertugas memberikan pelajaran berupa faktor-faktor dan pengetahuan hafalan kepada anak, melainkan tugas utama sekolah sekarang ialah mengajar bagaimana caranya belajar. Kepada anak cukup, diberikan pengetahuan kunci dan motivasi belajar yang memungkinkan mereka untuk belajar sepanjang hidupnya; (2) Sebagai konsekuensi fungsi yang disebutkan pertama, peranan guru makin sebagai partner anak didik dalam hal belajar; (3) Dalam rangka pandangan life long integrated education sendiri berfungsi sebagai pusat kegiatan belajar (leaming centre) bagi masyarakat di sekitarnya. Hal ini dimaksudkan agar ada jalinan hubungan antara sekolah dengan masyarakat dan agar anakanak tidak terasing dari masyarakat; dan (4) Sekolah tidak lagi merupakan sistem tertutup. Sekolah hendaknya selalu memberi kesempatan pada anak setiap saat untuk memperoleh pendidikan sehingga sekolah harus merupakan sistem yang terbuka, bagi anak-anak.

\section{Penutup}

Berdasarkan berbagai kajian dan pembahasan dapat disimpulkan bahwa:

a. Ada beberapa hal yang melatarbelakangi masyarakat berpandangan positif terhadap bomeschooling, yaitu pentingnya keunikan individu dalam belajar, ketidakpuasan masyarakat terhadap sistem pendidikan sekolah, dan anak-anak terlindung dari kekerasan;

b. Keuntungan bome schooling antara lain "siswa rumahan" justru lebih dewasa dan secara sosial lebih mampu menyesuaikan diri, dapat berinteraksi dengan orang-orang dari berbagai lapisan usia, dapat membuat pertanyaan, 
dan pertanyaan itu membuat anak termotivasi untuk melihat jawaban dari pertanyaannya, dan anak benar-benar dapat bekerja secara mandiri tanpa dipengaruhi guru maupun teman lainnya;

c. "Pelajar rumahan" mampu mengembangkan disiplin yang lebih besar dan secara otomatis mereka man belajar tanpa tergantung pada orang lain. Mereka berinisiatif menemukan sesuatu yang perlu diketahuinya, dan orangtua menjadi pendamping yang dibutuhkan untuk aktif mencari informasi;

d. Dengan belajar di rumah, anak-anak tidak lagi menunggu untuk diajar. Mereka sudah terbiasa mengelola pelajaran sendiri, mengikuti rencana belajarnya sendiri, yang jelas semua ini menjadi bagian alamiah dari pendidikan mereka; dan

e. Home schooling bisa menjadi model pendidikan alternatif di tengah keraguan terhadap mutu pendidikan, sekaligus sebagai jalan keluar atas mahalnya biaya sekolah.

\section{Endnotes}

${ }^{1}$ Yusufhadi Miarso, Menyemai Benih Teknologi Pendidikan (Jakarta: Pranada Media, 2004).

${ }^{2}$ Lebih lanjut dapat dibaca pada Undang-undang No. 20 Tahun 2003 tentang Sisdiknas berkaitan dengan Tujuan Pendidikan NasionaL.

${ }^{3}$ Basrowi, "Apresiasi Masyarakat Bandar Lampung Terhadap Home Schooling", dalam Jurnat Inovasi, Vol. I No 3 Oktober 2006 (Purworejo: Dinas Pendidikan Kab. Purworejo, 2006).

'Ibid.

${ }^{s}$ Robert Brumbaugh, Philosophers on Education (Boston: Houghton Miffin Company, 1963), hal. 124-153.

6 Gentle Spirit Magazine, VoL. 6 Number 9, 1999.

'Basrowi, "Apresiasi Masyarakat...".

' Yusufhadi Miarso, Menyemai..., (2004), hal. 623-624.

\section{Daftar Pustaka}

Basrowi. 2006. "Apresiasi Masyarakat Bandar Lampung Terhadap Home Schooling", dalam Jumal Inovasi, Vol. I No. 3 Oktober 2006. Purworejo: Dinas Pendidikan Kab. Purworejo. 
Koestoro, Budi dan Basrowi. 2006. Strategi Penelitian Sosial dan Pendidikan. Surabaya: Yayasan Kampusina Surabaya.

Brumbaugh, Robert. 1963. Philosophers on Education. Boston: Houghton Miffin Company.

Gentle Spinit Magazine, Vol. 6 No. 9/1999.

Miarso, Yusufhadi. 2004. Menyemai Benih Teknologi Pendidikan. Jakarta: Pranada Media.

R.M. Max Iver dan Charles B. Page. 1957. Society An Introduction Analysis. New York: Rina Heart and Company Inc. 